\title{
Formação do enfermeiro: características do professor e o sucesso escolar
}

\author{
Nurse's training: professor's characteristics and academic success \\ Formación de enfermería: características del professsor y su éxito escolar
}

Maria Romana Friedlander

Professora e Coordenadora de Investigação da Escola Superior de Enfermagem São Vicente de Paulo, Lisboa. Doutora pela Universidade de São

Paulo.

mrfriedlander@yahoo.com.br

\section{Maria Teresa de Arbués Moreira}

Coordenadora, Professora e Presidente do Conselho Cientifico da Escola Superior de Enfermagem São Vicente de Paulo, Lisboa, Portugal. Mestre em Enfermagem pela Universidade Católica Portuguesa. t.arbues.moreira@sapo.pt
Submissão: 20/09/2005 Aprovação: 09/03/2006

\section{RESUMO}

Descreve as características do professor que leciona as disciplinas que obtiveram os maiores índices de sucesso na avaliação realizada pelos estudantes. Foi realizado numa escola de ensino superior de enfermagem de Lisboa (Portugal), com 16 professores que responderam um questionário. Concluiu-se que o professor bem avaliado pelos estudantes possui os seguintes atributos: é maduro, bem qualificado para o ensino, com sólida experiência na docência e boa experiência no exercício da profissão. Na opinião dos próprios professores, são capazes de estabelecer um bom relacionamento com seus alunos, acreditam-se eficazes na prática docente e possuem um profundo conhecimento de sua disciplina. Todos utilizam a aula expositiva com interação e diálogo com os alunos, e complementada por experiências e vivências práticas, debates, discussões, dramatizações e simulações. As autoras alertam para a necessidade de outras pesquisas sobre o tema.

Descritores: Educação em enfermagem; Bacharelato em enfermagem; Docente de enfermagem.

\section{ABSTRACT}

The present report describes the characteristics of the professor who teaches the disciplines that obtained the highest success indexes in the evaluation carried out by the students. It was executed at a Nursing Superior Education School in Lisbon (Portugal), regarding 16 professors who answered a questionnaire. We concluded that a professor who is well evaluated by the students has the following attributes: he is mature, well qualified for education, with a solid experience in teaching and a good experience in the exercise of the profession. In the professor's own opinion, they are able to establish a good relationship with their students, they consider themselves as being solidly efficient in teaching practice and they have a deep knowledge of their lectured disciplines. All of the professors use expository lectures, with student's interaction and dialogue, and complemented by the sharing of experiences and practical way of life, debates, discussions, dramatisations and simulations. The authors alert the need for further research on the subject.

Descriptors: Education, nursing; Education, nursing, baccalaureate; Faculty, nursing.

\section{RESUMEN}

Describe las características del profesor de las asignaturas que tuvieran mejores índices de resultados en la evaluación realizada por los estudiantes. Fue realizada por una escuela de enseñanza superior de enfermería en Lisboa (Portugal) con 16 profesores que respondieron a un cuestionario. Se concluyó que el profesor evaluado altamente por los estudiantes posee las siguientes características : maduro, bien cualificado para enseñar, con sólida experiencia en la enseñanza y buena práctica en la ejecución de la profesión. En la opinión de los profesores, estos son capaces de establecer una buena relación con sus alumnos, son eficaces en la practica de la enseñanza y poseen un profundo conocimiento de su disciplina. Todos utilizan las clases como interacción y dialogo con los alumnos y lo complementan con experiencias y vivencias practicas, debates, discusiones, dramatizaciones y simulaciones. Las autoras alertan de la necesidadede de otras pesquisas sobre el tema.

Descriptores: Educación en enfermeria; Bachillerato en enfermería; Docente de enfermería.

Friedlander MR, Moreira MTA. Formação do enfermeiro: características do professor e o sucesso escolar. Rev Bras Enferm 2006 jan-fev; 59(1): 9-13.

\section{INTRODUÇÃO}

Em Portugal, as Escolas Superiores de Enfermagem são submetidas periodicamente a avaliações, do curso ou da escola, para as quais o Ministério da Ciência, Tecnologia e Ensino Superior exige o levantamento de uma série de dados. Entre eles, quando se trata da avaliação do curso, as escolas devem levantar a opinião dos estudantes sobre os professores de cada uma das unidades curriculares ministradas no curso de licenciatura (no Brasil, Curso de Graduaçãp). Além disso, algumas escolas, por decisão própria, também desencadeiam uma avaliação de forma a garantir dados para o seu aperfeiçoamento e como resposta à sua responsabilidade perante a 
sociedade a quem prestam os seus serviços. Essa última avaliação também inclui dados sobre os professores.

Dessa forma, pode-se deduzir que, tanto o Ministério como a instituição de ensino, pressupõem que o professor é um dos mais importantes agentes do processo de formação implementado pelas escolas superiores, e que a sua avaliação pode auxiliar a melhoria da educação.

A educação formal em enfermagem inclui um ser humano que, teoricamente, age sobre outro ser humano, o professor e o aprendiz, na qual o primeiro introduz o segundo na arte e na ciência da enfermagem com a finalidade de o capacitar para o exercício da profissão. Nas últimas décadas, as ciências humanas e sociais têm clarificado a compreensão sobre o papel da relação professor aluno sustentada por diversas abordagens pedagógicas

A qualidade do trabalho e do produto em qualquer instituição educacional é determinada e fundamenta-se nos seres humanos envolvidos nos seus processos. Uma investigação bastante criativa, demonstra que a qualidade dos licenciados depende muito mais do ensino ministrado em sala de aula e nos campos práticos do que dos outros componentes tais como conteúdos, disciplinas, currículos, estrutura da escola, instalações e outros ${ }^{(1)}$. Portanto, o professor e as suas características têm um significado e um impacto na qualidade do ensino que não podem ser desprezados pelos investigadores.

Um investigador da área da educação e autor de vários trabalhos de pesquisa ${ }^{(2)}$, com base num modelo proposto por Cuikshand, apresentou as variáveis que podem ter alguma relação com os resultados a serem obtidos e, entre elas, apontou as relacionadas com o professor. Esta indicação é confirmada por outros pesquisadores ${ }^{(3-5)}$. Esses últimos também discutem as pesquisas sobre o efeito do professor na qualidade do ensino e concluem que ainda não existem conclusões incontestáveis reforçando a necessidade de novos estudos. Acrescentam ainda que, as investigações especificamente relacionadas com as práticas de ensino são da maior importância.

Em resumo, algumas variáveis relacionadas com o professor, parecem despertar o interesse dos investigadores. Entre elas: conhecimento da matéria ${ }^{(1,5,6)}$, formação pedagógica ${ }^{(2)}$, relação aluno professor ${ }^{(2,3)}$ , práticas de ensino( ${ }^{(5)} e$ anos de experiência, idade, grau académico e estágios de especialização(2). Em relação às investigações realizadas, centradas nas variáveis referentes aos professores de enfermagem, a literatura ainda é muito escassa. Forrest ${ }^{(7)}$ realizou uma revisão de literatura sobre o ensino e os estilos de aprendizagem . Concluiu, entre outros aspectos, que a variedade de abordagens ou técnicas de ensino para atingir os variados estilos de aprendizagem dos alunos, é interessante, como também afirmaram Estrela e Ferreira( ${ }^{(5)}$, mas não explica a efectividade do ensino quando abordada do ponto de vista dos próprios alunos. Fritzpatrick(8) questionou a relação causa efeito referindo-se às características do professor e à sua eficácia no exercício dessa função. Chama a atenção para a importância do relacionamento professor-aluno que, em sua opinião, é uma vertente de grande interesse para os estudos da efectividade docente, destacadamente quando essa relação é observada e analisada sob o ponto de vista dos estudante.

Uma interessante investigação referente às percepções dos estudantes sobre os orientadores clínicos, ou supervisores de estágios clínicos, conclui que o relacionamento interpessoal, as características de personalidade e a aptidão para ensinar são apontados com maior freqüência nos orientadores efectivos quando comparados aos não efectivos. A competência profissional não mostrou diferença significativa entre os professores efectivos e os não efectivos. Na conclusão, os autores indicaram que a atitude do professor face aos alunos é o mais importante aspecto para explicar a eficácia do professor ${ }^{\left({ }^{(9)}\right.}$. Por último, na opinião de 353 estudantes de Singapura, as competências de ensino eram muito importantes, enquanto as relacionadas com o conhecimento teórico e de investigação receberam valores médios ${ }^{(10)}$. Os autores aconselharam estimular os professores a adquirirem e aplicarem capa- cidades relacionadas com o ensino e, bem assim, a pesquisa para inovarem a forma de ensinar.

No Brasil, Soares ${ }^{(10)}$, preocupada com a compreensão da acção docente, sob o ponto de vista do professor e do aluno, concluiu, que 0 docente deve envolver-se com os seus alunos, conhecer o conteúdo a ser leccionado e ter experiência clínica. Acrescentou que esse docente, ainda sob a visão do aluno, também deve apresentar facilidade ou capacidade para transmitir os conteúdos e reforçou a importância da relação professor aluno como factor determinante no processo educacional.

Há uma certa coerência entre os autores quando afirmam que as variáveis reportadas ao professor têm interesse para a pesquisa. Contudo, ainda não são evidentes as características que podem ser responsáveis pela eficácia e efectividade do professor, o que justifica a realização do presente estudo.

\section{OBJECTIVOS GERAL E ESPECÍFICO}

Identificar o perfil dos professores que ministraram as disciplinas que obtiveram maiores índices de sucesso na avaliação realizada pelos estudantes, com vista à melhoria da gestão escolar e consequentemente as políticas educacionais

Descrever as características dos professores que leccionam as disciplinas bem sucedidas, segundo os estudantes: idade, sexo, grau académico, vínculo à escola, formação, experiência, qualidade do relacionamento, do desempenho e da profundidade e actualização do conhecimento, as estratégias, meios audiovisuais e material de apoio utilizados e as características responsáveis pela boa avaliação, na visão do docente.

\section{MÉTODO ADOPTADO}

Trata-se de uma investigação descritiva e transversal, realizada numa Escola Superior de Enfermagem em Lisboa, não integrada numa Universidade ou Instituto Superior Politécnico.

Para a selecção dos 16 professores que constituíram a população deste estudo, analisaram-se os scores percentuais, atribuídos pelos alunos em 2004, às unidades curriculares do curso de licenciatura. As disciplinas curriculares (explicar o que são estas unidades pois antes falou-se em disciplinas) foram seleccionadas a partir dos seguintes critérios:

a) serem de natureza teórica,

b) de presença obrigatória,

c) não utilizarem metodologias muito diferenciadas como as unidades curriculares denominadas "Monografia" e "Seminário",

d) serem avaliadas pelos alunos com um índice maior que 86,3\% (média do score alcançado) no desempenho dos docentes. Assim, com a aplicação destes critérios, seleccionaram-se 7 unidades curriculares.

Foram considerados professores das disciplinas, aqueles que ministraram mais de 4 horas de aula, ou seja, não se considerou como docente 0 conferencista convidado eventualmente. Inicialmente, sob esses critérios, foram selecionados 21 professores, mas apenas 16 $(76,2 \%)$ responderam ao questionário aplicado.

Para a colheita dos dados foi elaborado um instrumento com 11 questões abertas e 3 questões para serem respondidas por meio de uma escala de valores de 0 a 10 . Este questionário é iniciado por um texto que descreve o objectivo do estudo e explicita a respectiva autorização para os dados serem utilizados na investigação, sem a identificação do respondente.

A primeira versão do questionário foi submetida a um teste piloto com 5 professores da mesma escola, que não faziam parte da população seleccionada. Após as modificações sugeridas, o questionário foi entregue aos elementos da amostra que tiveram cerca de 10 dias para o seu preenchimento e o entregaram diratamente para as autoras.

A análise dos resultados quantitativos foi auxiliada por uma tabela 
mestra electrónica, programada especialmente para esse fim, e elaborada com o programa Microsoft Excel. A análise qualitativa seguiu os passos sugeridos por Bardin ${ }^{(11)}$, contudo, o facto de se tratar de respostas a perguntas directas, simplificou significativamente essa análise.

\section{RESULTADOS}

As características populacionais podem ser observadas na Tabela abaixo.

Tabela 1. Características populacionais.

\begin{tabular}{lcc}
\hline \multirow{2}{*}{ Características } & \multicolumn{2}{c}{ Professores } \\
\cline { 2 - 3 } & $\mathbf{n}$ & $\%$ \\
\hline Idade (média: 50,1 anos) & 7 & 43,8 \\
$\quad$ Acima da média & 9 & 56,2 \\
$\quad$ Abaixo da média & & \\
Sexo & 15 & 93,8 \\
$\quad$ Feminino & 1 & 6,2 \\
$\quad$ Masculino & & \\
Preparação acadêmica & 4 & 25,0 \\
$\quad$ Especialista & 12 & 75,0 \\
Mestre & & \\
Vínculo institucional & 14 & 87,6 \\
$\quad$ Efectivo & 1 & 6,2 \\
$\quad$ Eventual & 1 & 6,2 \\
$\quad$ Conferencista & & \\
Anos de formação (média: 27,1 anos) & 6 & 42,9 \\
$\quad$ Acima da média & 8 & 57,1 \\
Abaixo da média & & \\
Anos de exercício (média 13,5 anos) & 4 & 28,6 \\
$\quad$ Acima da média & 10 & 71,4 \\
Abaixo da média & & 42,9 \\
Anos de docência (média 19,5 anos) & 6 & 57,1 \\
$\quad$ Acima da média & 8 & \\
Abaixo da média & & \\
\hline
\end{tabular}

* Nota: 1 professor não era enfermeiro e 1 professor não respondeu à questão.

${ }^{* *}$ Nota: 1 professor não é docente e 1 professor não respondeu à questão.

Em relação à idade dos docentes estudados, nota-se que não se trata de um grupo muito jovem dado que a média é alta, e a maioria dos professores tem idade abaixo da média, porém, na faixa etária dos 40 . A experiência de vida e a maturidade intelectual talvez possam explicar este facto. Observa-se ainda que, entre os docentes com alto grau de aprovação pelos estudantes, há uma predominância acentuada de profes-sores com o título de mestre, ou seja, que receberam alguma preparação para a docência. Esse resultado coincide com a opinião de Tuckman (2), que afirma ser a formação pedagógica uma variável de interesse para os estudos sobre a produção de resultados na educação.

Quanto ao vínculo institucional é importante salientar que a maioria absoluta de professores da escola estudada é docente efectivo. Esta situação de efectividade do professor, provavelmente, favorece um maior compromisso do professor em relação à qualidade do ensino e do desempenho dos seus alunos. Os resultados relacionados com os anos de formação profissional indicam que se trata de um grupo com experiência razoável.

No que concerne aos anos de exercício como enfermeiro, nota-se que os alunos não apontaram como excelentes professores aqueles com mais experiência na profissão, ou seja, $71,4 \%$ dos professores selecionados pelos alunos têm um número de anos de exercício abaixo da média. Tang, Chou e Chiang ${ }^{(9)}$, quando se referiam aos orientadores clínicos, também encontraram resultados coerentes que indicavam que a competência como enfermeiro não mostrou uma qualidade dos orientadores de estágio destacadamente apreciada pelos estudantes.

Finalmente, no que se relaciona com os anos de docência verificouse que a média é alta $(19,5)$, contudo, a maioria absoluta de professores de sucesso apontados pelos estudantes estão abaixo dessa média mas, acima de 10 anos. Parece que os bons professores não são necessáriamente os mais experientes mas, têm uma considerável experiência.

A seguir, na Tabela 2 apresentamos os resultados relacionados com a opinião dos professores relativamente a outras variáveis.

Tabela 2. Atributos auto-avaliados pelos professores.

\begin{tabular}{lcc}
\hline \multirow{2}{*}{ Atributos } & \multicolumn{2}{c}{ Score obtido } \\
\cline { 2 - 3 } & $\mathbf{n}$ & $\%$ \\
\hline Qualidade do relacionamento com os & 128 & 85,3 \\
alunos* & 110 & 79,1 \\
Eficácia do desempenho docente** & & \\
Profundidade e actualização do & 123 & 82,0 \\
conhecimento sobre a sua disciplina & &
\end{tabular}

* Nota: 1 professor não respondeu à questão.

** Nota: 2 professores não responderam à questão.

Em relação aos atributos apresentados na Tabela 2, deve-se chamar a atenção para o facto de ter sido solicitado, aos professores, que atribuíssem uma nota de zero a dez. Portanto, o score máximo possível, e que corresponde a $100 \%$, seria o resultado do número de respondentes multiplicado pela nota dez. Em relação aos três atributos verifica-se ser muito alta a auto-avaliação dos docentes, o que quer dizer que eles se consideram professores com bom relacionamento com os alunos, com conhecimentos profundos e actualizados sobre a respectiva disciplina e com bom desempenho. De facto, não apareceu nenhum professor que tenha atribuído a si próprio nota abaixo de 6 . Isto indica que parece importante a crença do docente nos seus atributos docentes.

Os resultados de nossa análise coincidem com os das pesquisas realizadas por Fritzpatrick ${ }^{(8)} \mathrm{e}$ Tang, Chou e Chiang ${ }^{(9)}$ no que concerne à importância do relacionamento professor-aluno para a eficácia do desempenho do professor, sob o ponto de vista dos estudantes. Chamamos a atenção para os resultados da investigação realizada por Tan e $\operatorname{Lim}^{(10)}$ que evidenciou a valorização média atribuída pelos alunos ao conhecimento teórico do professor.

Devido à importância que a literatura atribui ao relacionamento professor-aluno para explicar a eficácia do professor, tentámos observar a existência de alguma associação entre essa variável e a idade, os anos de formação e os anos de experiência docente. Os resultados da aplicação do teste do qui-quadrado não mostraram a existência de nenhuma associação.

Finalmente, os resultados relacionados com a análise de discurso foram os seguintes.

Tabela 3. Estratégias de ensino usadas pelos professores.

\begin{tabular}{lcc}
\hline \multirow{2}{*}{ Estratégias } & \multicolumn{2}{c}{ Professores } \\
\cline { 2 - 3 } & $\mathbf{n}$ & $\%$ \\
\hline Aula expositiva com diálogo e interacção & 12 & 75,0 \\
Uso de experiências e vivências práticas & 7 & 43,8 \\
Discussão e debates & 7 & 43,8 \\
Dramatização e simulação & 6 & 37,5 \\
Trabalhos de grupo orientados & 5 & 31,3 \\
Reflexão & 3 & 18,8 \\
Apresentação de trabalhos em sala de aula & 3 & 18,8 \\
Pesquisa bibliográfica & 2 & 12,5 \\
Uso de casos clínicos e depoimentos de doentes & 2 & 12,5 \\
Solução de problemas & 1 & 6,3 \\
Entrevistas & 1 & 6,3 \\
\hline
\end{tabular}

Observando-se a Tabela acima, nota-se que houve uma predominância do uso de métodos activos porque, mesmo os docentes que informaram usar as aulas expositivas, acrescentaram a interacção com os alunos, o diálogo ou a liberdade para a colocação de questões. Este resultado coincide com as observações dos teóricos quando discutem a aprendizagem dos adultos e as diferenças entre a andragogia e a 
pedagogia ${ }^{(12)}$. $O$ autor citado chama a atenção para o facto do adulto já ter acumulado, ao longo da vida, muitas experiências que influenciam as novas aprendizagens, e de darem preferência a métodos e conteúdos práticos que podem ser usados de imediato.

Observa-se, também, que a relação estratégia/professor é 3,1 o que indica o uso de técnicas variadas e reforça a conclusão da revisão da literatura apresentada por Forrest ${ }^{(7)}$.

Tabela 4. Recursos áudio visuais usados pelos professores.

\begin{tabular}{lcc}
\hline \multirow{2}{*}{ Recursos } & \multicolumn{2}{c}{ Professores } \\
\cline { 2 - 3 } & $\mathbf{n}$ & $\%$ \\
\hline Retroprojector & 14 & 87,5 \\
Data-show (projector com suporte informatizado) & 6 & 37,5 \\
Videofilmes & 3 & 18,8 \\
Projector de diapositivos & 2 & 12,5 \\
Quadro negro & 1 & 6,3 \\
Máquina de filmar & 1 & 6,3 \\
\hline
\end{tabular}

O auxilio dos recursos audiovisuais é amplamente aconselhado pela bibliografia especializada, uma vez que facilita a memorização porque utiliza os canais auditivos e visuais do estudante. Estes recursos constituiem importantes suportes para a aplicação dos conteúdos pois permitem trazer para a sala de aula as vivências e experiências ocorridas em qualquer ambiente. Os docentes deste estudo que, segundo os alunos, obtiveram sucesso, usaram, em média, por professor, 1,7 recursos mencionados.

Complementando esta questão dos recursos, quando questionados sobre o material de apoio distribuído aos estudantes durante as aulas, concluímos que:

- Todos os professores (100\%) utilizaram material escrito, tais como textos, artigos, documentos, resumos, livros ou capítulos, esquemas de aula e outros.

Tabela 5. Características pessoais ou de ensino que podem explicar o sucesso do professor junto dos alunos, na opinião do próprio docente.

\begin{tabular}{lcc}
\hline \multirow{2}{*}{ Características } & \multicolumn{2}{c}{ Professores } \\
\cline { 2 - 3 } & $\mathbf{n}$ & $\%$ \\
\hline Bom relacionamento entre professor e aluno & 8 & 50,0 \\
Envolvimento e disponibilidade do professor & 5 & 50,0 \\
Gostar do que faz/estar motivado & 5 & 31,2 \\
Respeito pelo outro & 4 & 25,0 \\
Domínio dos conteúdos ensinados & 4 & 25,0 \\
Capacidade de encorajar os alunos, suas acções, & & \\
sua autonomia e auto-aprendizagem & 4 & 25,0 \\
Capacidade de transmitir mensagens & 2 & 12,5 \\
Capacidade de escutar o outro & 2 & 12,5 \\
Acreditar n que transmite & 2 & 12,5 \\
Confiança no outro & 2 & 12,5 \\
Ser exigente & 2 & 12,5 \\
Humildade para aperfeiçoar-se & 2 & 12,5 \\
Compreensão & 2 & 12,5 \\
Capacidade de dialogar & 1 & 6,2 \\
Coerência & 1 & 6,2 \\
Assertividade & 1 & 6,2 \\
Autenticidade & 1 & 6,2 \\
Utilizar a articulação dos conteúdos & 1 & 6,2 \\
Tornar os alunos conscientes de seu papel & 1 & 6,2 \\
\hline
\end{tabular}

- Seis professores $(37,5 \%))$ citaram especificamente a indicação de bibliografia especializada.

- Um professor $(6,25 \%)$ apontou a indicação de filmes para complementar o conteúdo estudado.

- Um dos respondentes $(6,25 \%)$ indicou que entregava "planos de cuidados de enfermagem" aos seus alunos durante as aulas.

Finalmente, no que se relaciona com as características pessoais ou de ensino que, na opinião dos próprios docentes, poderiam explicar o seu sucesso junto dos estudantes, como principais características foram encontrados os resultados conforme apresentados na Tabela 5 .

Os resultados citados são coerentes com as opiniões de Zabala ${ }^{(3)}$, Tuckman $^{(2)}$, Soares ${ }^{(10)}$ e Fritzpatrick ${ }^{(8)}$, que enfatizaram o relacionamento professor e aluno como um aspecto de grande interesse para o estudo da eficácia docente no ponto de vista do estudante. O domínio do conteúdo foi uma das características importantes, segundo Demo ${ }^{(6)}$, Estrela e Ferreira ${ }^{(5)}$, Tuckman $^{(2)}$ e Soares ${ }^{(10)}$.

Nota-se que estes achados são coerentes e reforçam os resultados encontrados nas questões anteriores.

\section{CONCLUSÕES}

Observando-se as principais variáveis populacionais que caracterizam os professores aprovados pelos estudantes da escola estu-dada, verificou-se que se trata de um grupo maduro, bem qualificado para 0 ensino, com sólida experiência na docência e boa experiência no exercício da profissão.

Observou-se, na opinião dos próprios professores, que estes são capazes de estabelecer um bom relacionamento com os seus alunos, acreditam-se eficazes na prática docente e possuem um profundo conhecimento da sua disciplina.

Quanto às estratégias de ensino que os docentes utilizam, a aula expositiva com diálogo e interacção com os alunos é a mais utilizada, complementada por relatos de experiências e vivências práticas, debates, discussões, dramatizações e simulações. A utilização de material escrito como complemento das aulas é, também, uma prática docente adotada por todos os professores que obtiveram sucesso com os alunos. Os trabalhos em grupo com orientação também fazem parte do repertório docente. 0 equipamento áudio visual mais utilizado em sala de aula é o retroprojector e o projector com suporte informático. Parece que o relacionamento professor aluno não é influenciado pela idade do docente, seus anos de formação e sua experiência docente. Quando o professor explica seu bom desempenho ele 0 atribui também ao bom relacionamento e acrescenta outros atributos, principalmente: disponibilidade e envolvimento, gostar do que faz, respeito pelos outros, domínio dos conteúdos ensinados, capacidade de encorajar os estudantes, seus comportamentos e atitudes, e a aprendizagem individual. O conhecimento sobre esses atributos pode orientar a tomada de decisão dos administradores escolares, preocupados com a qualidade do ensino oferecido pelas suas instituições, e minimizar problemas entre professores e alunos. As politicas educacionais relativas à docência em enfermagem podem tomar como base os resultados desta investi-gação para que estimulem a evolução e as melhorias na formação des-ses profissionais.

Para terminar gostaríamos de chamar a atenção dos leitores para o facto da pesquisa ter sido apenas realizada numa instituição o que a torna limitada e evidencia a necessidade de ser repetida noutras escolas e noutros contextos culturais.

\section{REFERÊNCIAS}

1. Narchi NZ. O uso de indicadores de desempenho institucional na avaliação de cursos técnicos de enfermagem [tese]. São Paulo (SP): Departamento de Enfermagem, Universidade Federal de São Paulo/ Escola Paulista de Medicina; 1999.
2. Tuckman B. Manual de investigação em educação. $2^{\mathrm{a}}$ ed. Lisboa (POR): Fundação Calouste Gulbenkien; 2002.

3. Zabala A. A prática educativa. Porto Alegre (RS): Artmed; 1998. 
4. Arends R. Aprendendo a ensinar. Alfragide (POR): McGraw-Hill de Portugal; 1997.

5. Estrela A, Ferreira J. Investigação em educação: métodos e técnicas Lisboa (POR): Editora Educa; 2001.

6. Demo P. Desafios modernos da educação. $7^{\mathrm{a} e d}$. Petrópolis (RJ): Editora Vozes; 1993

7. Forrest S. Learning and teaching: the reciprocal link. J Continuing Educ Nurs 2004 mar-apr; 35(2): 74-9.

8. Fitzpatrick JJ. Evaluating teaching effectiveness. Nurs Educ Perspectives 2004 may-jun; 25(3): 109-10.
9. Tang FI, Chou SM, Chiang HH. Students' perceptions of effective an ineffective clinical instructors. J Nurs Educ 2005 apr; 44(4): 187-92.

10. Soares MAL. Compreendendo a ação do docente no processo educacional de um curso de graduação de enfermagem: o olhar dossujeitos envolvidos [tese]. São Paulo (SP): Escola de Enfermagem, Universidade de São Paulo; 2004.

11. Bardin LL. Analyse de contenu. $4^{\text {a }}$ ed. Paris (FRA): Presses Universitaires de France; 1986.

12. Knowles MS. The adult learner: a negleted species. $5^{\mathrm{a}}$ ed. USA: Gulg; 1990. 